\title{
LA SUSPENSIÓN DE FAENA POR ACCIDENTE LABORAL FATAL O GRAVE*
}

\section{JAIME ARANCIBIA MATTAR**}

RESUMEN: El trabajo aborda la naturaleza jurídica, presupuestos y supervisión del deber de suspensión de faenas por accidente laboral fatal o grave regulado en la ley 16.744. Concluye que se trata de una carga legal cuya regulación en términos abstractos da lugar a interpretaciones diversas. Propone, por tanto, una interpretación específica de los términos "accidente grave" y "faena afectada", necesarios para exigirla de modo cierto.

PALABRAS CLAVE: Suspensión de faena; Accidente fatal o grave.

\section{WORK STOPPAGE DUE TO FATAL OR SERIOUS OCCUPATIONAL INJURY}

ABSTRACT: This paper discusses the legal nature, conditions and supervision of the duty to stop working activities in case of fatal or serious occupational injury regulated in Act 16.744 . It holds that such a duty is a legal burden whose vague wording allows different interpretations. Therefore, it proposes a specific legal construction of terms such as "serious injury" and "affected working activities", which is necessary to ensure legal certainty among the regulatee.

KEY WORDS: Work stoppage; Fatal or serious occupational injury.

Sumario: Introducción. 1) Naturaleza de la suspensión de faenas: carga pública. 2) Contenido del deber de suspensión de faenas afectadas. (2.1.) Accidente grave. (2.2.) Faena afectada. (2.3.) Suspensión de la faena afectada sin perjuicio de las actividades de subsanación. (2.4.) Necesidad de actividad inherente a la faena para subsanar deficiencias. Conclusiones. Bibliografía. 


\section{INTRODUCCIÓN}

Este trabajo tiene por objeto analizar jurídicamente el deber del empleador de suspender faenas en caso de "accidentes del trabajo fatales y graves" conforme al artículo 76 de la ley 16.744, sobre Accidentes del Trabajo y Enfermedades Profesionales ${ }^{1}$.

Según esta normativa, la suspensión debe ser adoptada inmediatamente por el empleador y ratificada por la Inspección del Trabajo o por la Secretaría Regional Ministerial de Salud respectiva. En caso de incumplimiento de dicho deber, corresponde a estos órganos ordenar directamente la suspensión e imponer la multa correspondiente. La suspensión solo podrá alzarse una vez que "se verifique que se han subsanado las deficiencias constatadas" 2 . De lo contrario, el infractor será sancionado con multa a beneficio fiscal ${ }^{3}$.

La exigencia de este deber da origen a interrogantes jurídicas relevantes. Así, por ejemplo, el ejercicio de potestades concurrentes entre los órganos fiscalizadores genera problemas de coordinación y seguridad jurídica. La expresión faena "afectada", por su parte, requiere de una precisión mayor, pues de esta depende el alcance material de la suspensión y, por tanto, el presupuesto de la infracción. Además, conviene identificar el tipo de actividades de "subsanación" de riesgos que se pueden realizar durante la suspensión y que, por tanto, no constituyen una vulneración de la misma.

Para efectos de lo anterior, este trabajo se dividirá en dos secciones. La primera analizará la naturaleza jurídica de la suspensión de faenas, para concluir que se trata de una carga pública legal cuyo incumplimiento puede ser corregido a través de órdenes directas o multas de la autoridad competente. La siguiente sección abordará el contenido mismo de la medida, específicamente, los casos de accidente fatal o grave en que procede, el alcance de la expresión "faena afectada", y las exigencias relativas a las actividades de exploración y subsanación de las causas del accidente.

1 Congreso NaCiOnal (1968) Ley No 16.744. "Establece normas sobre accidentes del trabajo y enfermedades profesionales". Santiago: Diario Oficial 1 de enero de 1968. Cabe precisar que la medida de suspensión de faenas por accidentes laborales también ha sido atribuida a los inspectores fiscales de obras públicas: DiRECCIÓN GENERAL DE OBRAS PúbliCAS (2009) Resolución $\mathrm{N}^{\circ} 258$ "Modifica y fija el texto refundido de la Resolución $N^{\circ} 48$ de 2009 sobre Bases Administrativas para Contratos de Obras Públicas, Construcción y Conservación y fija texto refundido de la citada Resolución DGOP No 48, y sus modificaciones". Disponible en http://fiscalia.mop.cl [fecha de visita 18 de abril de 2016]. Este trabajo no abordará los alcances jurídicos de esta medida en particular sino únicamente aquella prevista en la ley 16.744 .

2 Art. 76 inciso $5^{\circ}$.

3 Art. 76 inciso final. 


\section{1) NATURALEza de LA SUSPENSIÓN DE FAENAS: CARGA PÚBLiCA REGULATORIA}

En derecho administrativo, la suspensión de actividades es una carga pública regulatoria, es decir, tiene por objeto prevenir un daño futuro a derechos individuales ante un riesgo serio e inminente de ocurrencia. Específicamente, se trata de una carga pública porque constituye un gravamen o deber libre, carente de acreedor determinado, que asume todo aquel que realiza una determinada actividad en su beneficio expuesta a determinados riesgos ${ }^{4}$.

En cuanto a sus características, se trataría de una carga legal, porque así lo exige la Constitución en materia de regulación económica (art. 19 No 21); ipso iure, es decir, opera por el solo ministerio de la ley sin necesidad de orden administrativa; conductual, pues impone un deber de hacer; suspensiva, en cuanto ordena la paralización temporal de una actividad; y preventiva de lesiones o correctiva de riesgos, dado que busca evitar un accidente laboral ante un riesgo presunto. En otras palabras, el atraso en suspender la faena siniestrada configura un periculum in mora o peligro de daño irreparable una vez que se logren solucionar las causas del accidente. En este sentido, la literatura comparada exige que el nivel de riesgo, según la experiencia y conocimiento del inspector, sea inaceptable 5 e inminen$\mathrm{te}^{6}$.

Sin perjuicio de lo anterior, cabe señalar que la normativa internacional concibe también la suspensión de faena como un derecho del trabajador. Es así como el Convenio 155 de 1981 de la Organización Internacional del Trabajo $(\mathrm{OIT})^{7}$, no ratificado por Chile, establece que "deberá protegerse de consecuencias injustificadas a todo trabajador que juzgue necesario interrumpir una situación de trabajo por creer, por motivos razonables, que esta entraña un peligro inminente y grave para su vida o su salud' (art.

4 Alessandri R., Arturo; Somarriva U., Manuel; Vodanovic H., Antonio (2009) Tratado de Derecho Civil, Tomo Primero. Santiago: Editorial Jurídica de Chile, pp. 401, p. 301. Para el concepto de carga en el derecho, ver también MAYER, Otto (1982) Derecho Administrativo Alemán. Tomo IV. Buenos Aires: Ediciones Depalma. pp. 374. p. 107 y ss; y LAGOS VILLAREAL, Osvaldo (2006) Las cargas del acreedor en el seguro de responsabilidad civil. Madrid: Fundación Mapfre, pp. 502. p. 3 a 19.

5 HOPKINS, Andrew (2007) "Beyond compliance monitoring: new strategies for safety regulators". Law and Policy, $\mathrm{N}^{\circ} 29$, p. 211.

6 APPLEBEY, George (1979) "British Legislation on health and safety work: appraisal after five years". Les Cahiers de Droit, p. 708 a 713.

ORGANIZACIÓN INTERNACIONAL DEL TRABAJO, Convenio sobre seguridad y salud de los trabajadores y medio ambiente de trabajo. Adoptado en Ginebra en la 67a reunión de la CIT, el 22 de junio de 1981. Entró en vigor el 11 de agosto de 1983. 
13), y que "mientras el empleador no haya tomado medidas correctivas, si fuere necesario, no podrá exigir de los trabajadores que reanuden una situación de trabajo en donde exista con carácter continuo un peligro grave e inminente para su vida o su salud' (art. 19 letra f) ${ }^{8}$. Pensamos que el riesgo constituye simplemente una presunción iuris tantum o simplemente legal derivada de la ocurrencia del accidente, es decir, una especie de fumus bonis iuris o buen olor del interés jurídico afectado. Luego, admite prueba en contrario. En este sentido, cabe precisar que la Corte Suprema ha sostenido que la mera ocurrencia de un accidente del trabajo no es causal suficiente para dar por acreditada la existencia de un riesgo antijurídico, siendo necesario probarlo 9 . Por esta razón, el empleador podría obtener el levantamiento de la medida suspensiva de la faena no solo al subsanar las deficiencias detectadas, sino también el acreditar que no existen tales deficiencias o riesgos prohibidos, y que el accidente se produjo por la imprudencia de la víctima o por caso fortuito o fuerza mayor.

Ante el incumplimiento de la carga legal de suspensión de faenas, los órganos competentes disponen de potestades de orden directa ${ }^{10} \mathrm{y}$ multa.

$8 \quad$ Ver VAN KERNER, Esther (1997) "The right of an employee to stop work in dangerous circumstances at the workplace: an international perspective on south African law", Industrial Law Journal Juta, $\mathrm{N}^{\circ}$ 18, p. 1198 a 1217; HILGERT, Jeffrey, "The future of workplace health and safety as a fundamental human right", Comparative Labor Law and Policy Journal, Vol. 34, 2012-2013, p. 715 y ss; TsHoOsE, Clarence (2014) "Placing the Right to Occupational Health and Safety within a Human Rights Framework: Trendsand Challenges for South Africa", Comparative and International Law Journal of Southern Africa, Vol. 47, Issue 2 (July), pp. 276-296.

9 Corte De Apelaciones De Temuco. 22 de marzo de 2011. Rol No 1127-2010. Disponible en www.vlex.com [fecha de visita 18 de abril de 2016]: "Que los antecedentes reunidos en el Sumario Administrativo son insuficientes para tener por establecidos los hechos en la forma prevista en el artículo 166 del Código Sanitario; que la circunstancia que durante los trabajos se hubiera producido un accidente no puede llevar necesariamente a la conclusión de que la faena realizada era altamente riesgosa, descartando a priori la posibilidad de un mero accidente; que sin perjuicio de lo anterior la resolución reclamada no señala concretamente qué infracción reglamentaria típica sanciona, lo que implica dejar sin fundamento la multa aplicada y consiguientemente, impide establecer si la sanción es la que corresponde a la eventual infracción cometida y ponderar la justicia de su monto" (Consid. $3^{\circ}$ )

"Que a mayor abundamiento, en la especie no existe el elemento causal que ligue el accidente ocurrido con una faena altamente riesgosa; en efecto, no puede descartarse a priori la posibilidad de un mero accidente, al no establecerse con absoluta precisión el entorno en que se realizaban las faenas y la cantidad, especie, peligrosidad y ubicación de los materiales que se encontraban en el lugar, de modo que mal puede sancionarse si no se descarta claramente la hipótesis de un accidente, lo que conduce necesariamente a la imposibilidad de aplicar una sanción a la empresa donde se realizaba la faena" (Consid. 4 ).

10 LEAL VÁsqueZ, Brigitte (2015) La potestad de inspección de la Administración del Estado. Santiago: Cuadernos del Tribunal Constitucional. $N^{\circ}$ 56. pp. 289, p. 54. La autora, siguiendo a García de Enterría, define la orden como "la imposición de un deber de hacer, no hacer o padecer mediante una decisión administrativa específica. Su característica esencial consiste en actualizar una anterior prescripción normativa de conducta, que reside generalmente en la ley". En este sentido, el Tribunal Constitucional ha señalado que la ley puede operar en 
La orden de suspensión puede ser adoptada por el SEREMI de Salud respectivo en virtud del artículo 178 del Código Sanitario ${ }^{11}$, que lo habilita, en su calidad de autoridad sanitaria sucesora del Director Regional de Salud (art. 5 del Código Sanitario), para imponer la medida sanitaria de "paralización de faenas... cuando exista un riesgo inminente para la salud". A su vez, la Inspección del Trabajo podría ordenar la suspensión de la faena en virtud de lo dispuesto en el artículo 28 de su ley orgánica ${ }^{12}$. La multa, por su parte, podría ser impuesta por dicho SEREMI o por el Inspector del Trabajo en virtud del artículo 76 inciso final de la ley 16.744 .

\section{2) CONTENIDO DEL DEBER DE SUSPENSIÓN DE FAENAS AFECTADAS}

El deber conductual que comentamos se estructura sobre la base de un hecho estimulante -accidente del trabajo fatal y grave-, un sujeto obligado -el empleador-, un objeto -suspender faenas afectadas- y una modalidad -de forma inmediata-. Tanto el hecho como el objeto mencionados han sido fuente de controversias interpretativas, que pasamos a revisar.

\section{(2.1.) ACCIDENTE GRAVE}

El precepto en cuestión exige la suspensión de faenas no solo ante accidentes fatales o mortales ${ }^{13}$ sino también "graves". Esta expresión ha

esta materia de dos maneras: "por una parte, puede establecer directamente el deber o la obligación. Por la otra, puede entregar a la Administración la singularización de esa situación pasiva. Aquí aparecen las órdenes". TRIBUNAL CONSTITUCIONAL. 10 de noviembre de 2013. Rol No 2264. "Requerimiento de inaplicabilidad por inconstitucionalidad presentado por CGE Distribución S.A. respecto del artículo 15, inciso primero, de la Ley $N^{o} 18.410$, que crea la Superintendencia de Electricidad y Combustibles". Disponible en www.tribunalconstitucional.cl [fecha de visita 18 de abril de 2016].

11 Congreso Nacional. Ministerio de Salud Pública (1968) D.F.L. N 725. "Código Sanitario". Santiago: Diario Oficial, 31 de enero de 1968.

12 Presidente de la República. Ministerio del Trabajo y Previsión Social (1967) Decreto con Fuerza de Ley No 2. "Dispone la reestructuración y fija las funciones de la Dirección del Trabajo". Santiago: Diario Oficial 29 de septiembre de 1967. Art. 28: "En el ejercicio de sus funciones fiscalizadoras, los Inspectores del Trabajo podrán ordenar la suspensión inmediata de las labores que a su juicio constituyen peligro inminente para la salud o vida de los trabajadores y cuando constaten la ejecución de trabajos con infracción a la legislación laboral".

13 Superintendencia de Seguridad Social (2007) Circular No 2.345. "Imparte instrucciones respecto de las obligaciones impuestas a las empresas por los incisos cuarto y quinto del artículo 76 de la ley $N^{\circ} 16.744$, en virtud de lo establecido en la ley $N^{\circ} 20.123$ ". Disponible en www. suseso.cl [fecha de visita 18 de abril de 2016]. Define accidente fatal como aquel que "pro- 
sido precisada por las autoridades sectoriales y la jurisprudencia judicial. De los diversos pronunciamientos se desprende que el accidente grave es aquel que provoca una incapacidad severa que impide al trabajador valerse por sus propios medios.

Así, por ejemplo, la Superintendencia de Seguridad Social (SUSE$\mathrm{SO})$ ha definido accidente del trabajo grave a "cualquier accidente del trabajo que: obligue a realizar maniobras de reanimación ${ }^{14}$, u obligue a realizar maniobras de rescate ${ }^{15}$, u ocurra por caida de altura, de más de $2 \mathrm{~m}, \mathrm{o}$ provoque, en forma inmediata, la amputación o pérdida de cualquier parte del cuerpo, o involucre un número tal de trabajadores que afecte el desarrollo normal de la faena afectada" 16 .

La misma autoridad ha precisado que su definición de gravedad "es de tipo operacional y no clinica ni médico legal, ya que tiene como finalidad que el empleador, que es quien debe cumplir con las obligaciones señaladas (suspender, evacuar e informar), reconozca con facilidad cuándo debe informar de lo ocurrido a las entidades fiscalizadoras, autosuspender la(s) faena(s) afectada(s) y mantenerla hasta que dichas entidades autoricen la reanudación" 17.

A su vez, la Dirección del Trabajo ha calificado como graves aquellos accidentes "que provoquen incapacidad temporal y/o invalidez, y aquellos que requieran hospitalización, como por ejemplo: Traumatismo Encéfalo Craneano (TEC), fracturas, politraumatismos, barotrauma, quemaduras, intoxicaciones severas y/o heridas complicadas, u otras, siempre que en cualquiera de estos casos tengan connotación pública o hayan sido difundidos por la

voca la muerte del trabajador en forma inmediata o durante su traslado a un centro asistencial' $(\mathrm{I}, 2, \mathrm{a})$.

14 Superintendencia de Seguridad Social (2007) Circular N².378. "Complementa instrucciones impartidas mediante circular $N^{\circ} 2.345$, de 10 de enero de 2007, respecto de las obligaciones impuestas a las empresas por los incisos cuarto y quinto del artículo 76 de la ley $N^{\circ}$ 16.744, en virtud de lo establecido en la ley $N^{\circ} 20.123$ ". Disponible en www.suseso.cl [fecha de visita 18 de abril de 2016]. En esta la SUSESO definió estas maniobras como "conjunto de maniobras encaminadas a revertir un paro cardiorrespiratorio, con la finalidad de recuperar o mantener las constantes vitales del organismo. Estas pueden ser básicas (no se requiere de medios especiales y las realiza cualquier persona debidamente capacitada); o avanzadas (se requiere de medios especiales y las realizan profesionales de la salud entrenados)" (II,1,b).

15 Superintendencia de Seguridad Social (2007) Circular N 2.378. Definió estas maniobras como "aquellas que permitan sacar al trabajador del lugar en que quedó, cuando este se encuentre impedido de salir por sus propios medios" (II, 1,b).

16 Superintendencia de Seguridad Social (2007) Circular N².345, (I,2,b).

17 Superintendencia de Seguridad Social (2010) Ordinario No 52.849. Disponible en www.suseso.cl [fecha de visita 18 de abril de 2016]. 
prensa, con excepción que estos afectaran a trabajadores en el trayecto directo de ida o regreso, entre la habitación y el lugar de trabajo o viceversa" 18 .

Por su parte, la jurisprudencia judicial, que no resulta obligada por la interpretación legal de los órganos administrativos, también ha precisado el sentido y alcance de la expresión accidente "grave".

Así, por ejemplo, un juez consideró grave la caída de un portón de supermercado sobre una trabajadora: "pudiendo apreciarse en dicho momento que estaba inconsciente, le sangraba la cabeza y tenía una pierna fracturada"19.

Adicionalmente, los tribunales han interpretado la expresión "grave" en relación a la invalidez o incapacidad de ganancia del trabajador en los términos de la ley 16.744 (art. 34 y ss.). En razón de este criterio, por ejemplo, ha rechazado calificar como grave el corte accidental del dedo pulgar que no compromete su estructura ósea, por no haberse registrado "secuelas ni pérdida de funcionalidad..."20. Asimismo, no revistió el carácter de grave una "herida cortante indice derecho con pérdida de sustancia... pérdida parcial de la uña y de tejido celular subcutáneo y piel del dedo indice derecho" 21 ; ni que un trabajador haya sido "golpeado por una viga en su pierna izquierda, que en el mismo momento el trabajador por sus propios medios, sacó su pierna debajo de la viga y se incorporó cojeando hacia un lugar seguro" 22 .

18 Dirección del Trabajo (2013), Orden de Servicio N². "Sistematiza, refunde y actualiza las instrucciones vigentes relativas a criterios de actuación frente a accidentes del trabajo y ocultamiento de accidentes del trabajo y enfermedades profesionales". Disponible en www.dt.gob.cl [fecha de visita 18 de abril de 2016]. I, 2, b.

19 Juzgado de Letras del Trabajo de Curicó. 14 de octubre de 2009. Rol No I-8-2009, consid. $8^{\circ}$. Disponible en www.vlex.com [fecha de visita 18 de abril de 2016].

20 Segundo Juzgado de Letras del Trabajo de Santiago. 18 de julio de 2014 . Rol N I-184-2014. Disponible en www.vlex.com [fecha de visita 18 de abril de 2016]: "De este modo, a partir de los antecedentes médicos incorporados, resulta evidente que la gravedad, entidad o importancia, de esta lesión no es comparable de modo alguno con aquellas amputaciones que requieren para su recuperación un largo tratamiento y que, además, suelen luego dejar secuelas, ocasionar algún tipo de incapacidad permanente, y hacer necesario el uso de elementos ortopédicos, nada de lo cual ha ocurrido respecto del actor, lo que desde ya permite cuestionar la alegación de la Inspección del Trabajo en cuanto a que toda amputación, entendida pura y simplemente como toda pérdida de una parte del cuerpo, sea sin distinción o matiz alguno calificable de grave" (consid. 8º).

21 Juzgado de Letras del Trabajo de Temuco. 8 de febrero de 2013. Rol N I-105-2012, consid. $11^{\circ}$. Disponible en www.vlex.com [fecha de visita 18 de abril de 2016].

22 Juzgado de Letras del Trabajo de Temuco. 21 de diciembre de 2012. Rol No I-83-2012, consid. $7^{\circ}$. Disponible en www.vlex.com [fecha de visita 18 de abril de 2016]. El fallo continúa seńalando que: "lo ocurrido no constituye un accidente del trabajo grave... no existieron maniobras de reanimación ni pérdidas del conocimiento del trabajador, no bubo una caida de altura superior a 2 metros, no hubo amputación o pérdida de partes del cuerpo, el accidente involucró a un trabajador, que no hubo maniobras de rescate, pues el trabajador no quedó atrapado con su cuerpo entero debajo de las vigas, sino que como lo señala él mismo tiró el pie y lo 
Tampoco sería grave el problema para respirar y las náuseas derivadas de la exposición a la inhalación de cloro, en aquellos casos en que "respecto de ninguna de ellas se les otorgó licencia médica alguna, fueron dadas de alta de manera inmediata y, más aún, concurren a su trabajo al día siguiente" 23 . Se descarta, además, el accidente de quemaduras, "salvo aquellas que impliquen la pérdida de cualquier parte del cuerpo"24; y la "contusión en su brazo derecho, producto del aprisionamiento de su brazo por Balde de máquina, que le ocasionó una incapacidad para el trabajo por un periodo de once dias" 25 .

Por último, se ha sostenido que la suspensión procede con la sola ocurrencia del accidente, con prescindencia de lo que declare el trabajador respecto de su propia negligencia en el $\mathrm{mismo}^{26}$.

\section{(2.2.) FAENA AFECTADA}

Ahora bien, ¿qué debemos entender por "faena"? El Diccionario de la Lengua Española la define en términos de labor, trabajo, servicio u operación $^{27}$. Luego, se refiere a una actividad. Sin embargo, cabe precisar que el órgano administrativo encargado de interpretar la ley concibe la faena en términos de lugar.

En efecto, la SUSESO, encargada legal de impartir las instrucciones sobre la forma en que el empleador deberá informar sobre la ocurrencia de accidentes (art. 76 inciso $4^{\circ}$ de la ley 16.744), ha identificado la faena como "área o puesto de trabajo..." ${ }^{28}$. Con todo, pensamos que esta definición de faena en términos de "zona" más que de "actividad" no es errada, si entendemos que se refiere más bien al ámbito espacial en que se

sacó, en ningún momento quedó inmovilizado, porque era prácticamente hormigón fresco el que le cayó encima, que no hubo fractura de la pierna sino que una contusión, quedando en observación por 4 dias en la mutual y posteriormente quedó en tratamiento de kinesiologí... el hecho de salir en camilla del lugar obedece obviamente a una medida de precaución tomada por la prevencionista de riesgos, porque el accidente sucedió en el quinto piso del edificio y no era prudente que el trabajador saliera caminando si tenía dolor en su pierna izquierda" (consid. $7^{\circ}$ ).

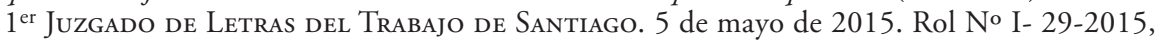
consid. $8^{\circ}$. Disponible en www.vlex.com [fecha de visita 18 de abril de 2016].

Juzgado de Letras y Garantía de Quintero. 22 de marzo de 2013. Rol No I-2-2012, consid. $11^{\circ}$. Disponible en www.vlex.com [fecha de visita 18 de abril de 2016].

Juzgado de Letras del Trabajo de Iquique. 25 de julio de 2011. Rol No I-4-2011, consid. $7^{\circ}$. Disponible en www.vlex.com [fecha de visita 18 de abril de 2016].

Juzgado de Letras del Trabajo de Calama. 20 de marzo de 2014. Rol No I-22-2013, consid. $10^{\circ}$. Disponible en www.vlex.com [fecha de visita 18 de abril de 2016].

Real Academia Española (2001) Diccionario de la lengua española (22.a ed.). Consultado en http://www.rae.es/rae.html.

Superintendencia de Seguridad Social (2007) Circular No 2.345 (2007) I. 2.c. 
desarrolla la actividad. Luego, debiéramos entender "faena" como la actividad desarrollada en un área determinada.

Para que opere la suspensión, la actividad debe estar, además, "afectada", es decir, menoscabada, perjudicada o influida desfavorablemente por algo ${ }^{29}$. Según la ley 16.744 , la afectación se produce por la mera ocurrencia del accidente y por la presunción simplemente legal de que este se produjo por "deficiencias" (art. 76).

A mayor abundamiento, la SUSESO define faena afectada como "área o puesto de trabajo en que ocurrió el accidente, pudiendo incluso abarcar la faena en su conjunto, dependiendo de las características y origen del siniestro, y en la cual, de no adoptar la empresa medidas correctivas inmediatas se pone en peligro la vida o salud de otros trabajadores" 30 .

La jurisprudencia judicial ha precisado que la expresión área o puesto de trabajo comprende también los accidentes de trayecto del trabajador fuera del lugar de la faena ${ }^{31}$. Además, las sentencias de los tribunales han interpretado tales términos conforme al principio de proporcionalidad.

Así, por ejemplo, ante un accidente de amputación de falange de dedo índice ${ }^{32}$, el juez sostuvo que "no requiere que se paralice toda una empresa" sino solamente el lugar "en que se desarrolla la misma función o labor del trabajador accidentado". Pero si tratara de un accidente con maquinaria, continúa este último fallo, no bastaría con suspender la máquina del trabajador accidentado sino toda la actividad relacionada con la misma.

Sin embargo, en otro caso, el tribunal estimó que el atropello de un trabajador que recoge desecho domiciliario por el camión que lo transporta obliga a la suspensión y revisión de todos los camiones relacionados con la actividad ${ }^{33}$. A nuestro entender, este pronunciamiento, expresado sin matices, es desproporcionado. Para efectos de suspender la actividad de todos los camiones habría que comprobar, al menos, que el siniestro se produjo por una falla mecánica o falta de revisión técnica del mismo.

La jurisprudencia también ha sostenido que, en el caso de accidentes de trabajadores de empresas contratistas, la "faena" continúa siendo

\footnotetext{
29 Real Academia Española (2001) Diccionario de la lengua española (22.a ed.). Consultado en http://www.rae.es/rae.html.

30 Superintendencia de Seguridad Social (2007) Circular No 2.345, I. 2.c.

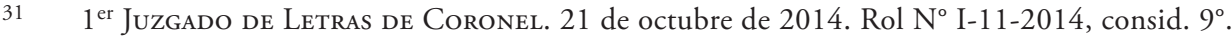
Disponible en www.vlex.com [fecha de visita 18 de abril de 2016].

32 Juzgado de Letras del Trabajo de Calama. 20 de marzo de 2014. Rol No I-22-2013, consid. $10^{\circ}$. Disponible en www.vlex.com [fecha de visita 18 de abril de 2016].

33 Juzgado de Letras del Trabajo de Talca. 19 de octubre de 2009. Rol No I-6-2009, consid. $8^{\circ}$. Disponible en www.vlex.com [fecha de visita 18 de abril de 2016].
} 
la empresa principal. En consecuencia, por ejemplo, no correspondería suspender labores por intoxicación alimenticia de un alto porcentaje de trabajadores de la empresa contratista que constituyen, asimismo, un porcentaje menor de los trabajadores de la empresa principal en que se desempeñan ${ }^{34}$. En otras palabras, semejante accidente no sería grave "porque no tuvo la entidad exigida por la norma para afectar a un número tal de trabajadores que impida el desarrollo normal de la faena" 35.

La Dirección del Trabajo, por su parte, precisa que solo ameritan suspensión aquellas "deficiencias y/o infracciones que ponen directamente en peligro la vida o seguridad de los trabajadores y no de infracciones en materia de higiene y seguridad, que si bien son sancionables no dan lugar a la suspensión de la obra o faena" ${ }^{36}$. Se destaca entonces que el vínculo de causalidad entre la posible deficiencia y el peligro que causa a los trabajadores debe ser directo, descartando así hipótesis de causalidad indirecta. En otras palabras, las deficiencias, de existir, deben ser causa inmediata o próxima del accidente informado. Así lo confirma la misma Dirección, al permitir el levantamiento de la suspensión una vez que "la empresa hubiese subsanado las causas del accidente fatal o grave" 37 .

De lo dicho se desprende que la "faena afectada" es una actividad desarrollada en un lugar específico, que ha servido de ocasión para un accidente fatal o grave, causado presumiblemente y de modo directo por deficiencias o infracciones administrativas que afectan la salud o vida del trabajador.

\section{(2.3.) SUSPENSIÓN DE LA FAENA AFECTADA SIN PERJUICIO DE LAS ACTIVIDADES DE SUBSANACIÓN}

El Diccionario de la Lengua Española define suspender como "detener o diferir por algún tiempo una acción u obra"38. En consecuencia, la suspensión de la faena afectada consiste en la detención por un tiempo de aquella actividad desarrollada en un lugar específico, que ha servido de

\footnotetext{
34 Primer Juzgado de Letras de Santa Cruz. 29 de enero de 2015. Rol Nº I-25-2014, consid. $8^{\circ}$. Disponible en www.vlex.com [fecha de visita 18 de abril de 2016].

35 Primer Juzgado de Letras de Santa Cruz. Rol No I-25-2014.

36 Dirección del Trabajo (2007) Orden de servicio $\mathrm{N}^{\circ}$ 7. "Imparte criterios de actuación e instrucciones para la aplicación de las normas referidas a la obligación de notificación de accidentes del trabajo fatales y graves y la obligación de autosuspensión de la obra o faena". Disponible en www.dt.gob.cl [fecha de visita 18 de abril de 2016].

37 Dirección del Trabajo (2007) Orden de servicio $\mathrm{N}^{\circ} 7,2.6 . \mathrm{b}$ ).

38 Real Academia Española (2001) Diccionario de la lengua española (22.a ed.). Consultado en http://www.rae.es/rae.html.
} 
ocasión para un accidente grave, causado presumiblemente y de modo directo por deficiencias o infracciones administrativas.

En virtud de esta definición, el deber legal de suspensión se entendería incumplido en las siguientes tres hipótesis: a) No suspender inmediatamente o continuar desarrollando la actividad; b) suspender y reanudar la actividad sin autorización del fiscalizador; y c) realizar cualquier conducta inherente a dicha actividad, aunque no constituya reanudación, sin validación de la autoridad competente. Esta última hipótesis se funda en que lo relevante de la suspensión es el riesgo específico y directo que genera la faena más que la descripción específica de cada conducta de la faena que lo afecta. Un antiguo adagio jurídico señala que conviene atender al sentido de la norma más que a las palabras ${ }^{39}$.

Es por esta razón que, por ejemplo, un buque pesquero fue multado por realizar actividades estando anclado en el puerto. La empresa dueña de la nave impugnó la sanción porque, a su juicio, una faena pesquera solo se entendía reanudada con el zarpe de la nave. Sin embargo, la Corte sostuvo que la reanudación no solo comprende la actividad misma sino también las gestiones preparatorias de la misma ${ }^{40}$.

Siendo esto así, ¿es posible desarrollar algún tipo de actividad en la faena afectada que no vulnere la suspensión?

Suspendida la actividad que sirvió de ocasión al accidente, la ley señala que el empleador solo podrá realizar aquellas actividades que tengan por objeto eliminar el riesgo que pudo haber causado el accidente. Específicamente, "deberá permitir a los trabajadores la evacuación del lugar de trabajo" y subsanar las deficiencias constatadas (art. 76 inciso $5^{\circ}$ de la ley 16.744). La SUSESO precisa, además, que "El ingreso a estas áreas, para

39 Melius est sensum magis quam verba amplecti (Ulpiano, D. 34.4.3.9). Ver Domingo, Rafael y Rodríguez-Antolín, Beatriz, (2000) Reglas jurídicas y aforismos. Madrid: Editorial Aranzadi, pp. 227, p. 38.

40 Corte de Apelaciones de Iquique. 3 de julio de 2015. Rol Nº 32. Resolución No 9.404. Consid. 4º. Disponible en www.vlex.com [fecha de visita 18 de abril de 2016]: "siendo la nave un buque de pesca y por tanto la pesca su finalidad última y sus labores por esencia, se debe considerar que para que esa nave y su tripulación puedan desarrollar dichas labores de pesca se requiere necesariamente de labores previas como la reparación de las redes de pesca y mantenimiento adecuado de los motores y maniobras de pesca. La primera de estas labores son propias del personal de rederas y las segundas del oficial Motorista de la nave. Lo anterior, entonces, lleva a la conclusión que ese personal a bordo, rederas y motorista, estaba realizando labores previas imprescindibles para la pesca y por lo tanto corresponde considerarlas como una reanudación de faenas propiamente tal, de manera que no existe vicio alguno en el consentimiento del trabajo sobre ese punto". 
enfrentar y controlar el o los riesgo(s) presente(s), solo deberá efectuarse con personal debidamente entrenado y equipado" 41 .

Por lo tanto, la suspensión de la faena afectada no implica la prohibición absoluta de actividad en el área, pues se permiten aquellas destinadas a evacuar trabajadores, investigar las causas de lo sucedido y subsanar las deficiencias detectadas si las hubiere.

\section{(2.4.) NECESIDAD DE ACTIVIDAD INHERENTE A LA FAENA PARA SUBSANAR DEFICIENCIAS}

En este punto, sin embargo, surge la interrogante siguiente: ¿qué ocurre si la revisión o corrección de las deficiencias exige realizar una de las conductas inherentes a la faena suspendida? Hablamos de una conducta cuyo objeto - no así su fin- estaría comprendido dentro del riesgo ilícito que justificó la paralización.

Pensamos que la realización de dicha conducta no constituiría una vulneración de la suspensión en la medida que cumpla los siguientes requisitos: a) que sea necesaria para constatar o corregir deficiencias; b) que haya contado con un plan de prevención del riesgo prohibido que justificó la suspensión, revisado por autoridad competente; y c) que se haya cumplido dicho plan en la práctica.

Luego, para saber si una conducta específica vulneró o no la medida de suspensión o el interés protegido corresponde someterla a un test de tres preguntas: Primero, ¿tenía la conducta una finalidad de investigación o subsanación de las deficiencias constatadas? Segundo, ¿tenía la empresa un plan de prevención de riesgos específicos para la operación? En tercer lugar, ¿`se realizó la conducta conforme al plan de prevención de riesgos?

La mera ocurrencia del accidente fatal tampoco permite concluir el incumplimiento del plan, pues podría obedecer también a la infracción de un deber de seguridad asociado a un riesgo distinto -ilícito diferente-, a la imprudencia de la víctima, o a un caso fortuito.

Incluso más, podría darse la hipótesis de que el accidente se produjo por el cumplimiento fiel de un criterio erróneo del órgano fiscalizador. En este caso no podría sancionarse porque, de acuerdo al artículo 45 del Código Civil, los actos de autoridad corresponden a una causal de fuerza mayor o caso fortuito que exime de responsabilidad.

41 Superintendencia de Seguridad Social (2007) Circular No 2.345, Procedimiento $N^{\circ} 1$, II, 1. 
Cumplidos los requisitos anteriores, a nuestro juicio, la conducta estaría amparada por la norma que permite realizar actividades destinadas a revisar y subsanar las deficiencias constatadas.

Ahora bien, ¿qué pasaría si durante las labores de revisión o reparación se produce un riesgo prohibido diferente al que justificó la medida suspensiva o al plan de prevención de riesgos ad hoc? A nuestro juicio, dicha infracción no constituiría una vulneración de la medida suspensiva, sino que un ilícito diferente. Por tanto, debiera ser objeto de un tratamiento procedimental y sancionador ex novo.

Por último, ¿cuál es el órgano encargado de fiscalizar el plan de riesgos asociados a la revisión y subsanación de deficiencias al interior de la faena paralizada?

A nuestro entender, dicha fiscalización corresponde al órgano que refrendó o decreto la suspensión en los términos de la ley 16.744, a menos que el legislador haya atribuido dicho poder a un órgano especializado.

En el ámbito minero, por ejemplo, dicha función correspondería más bien al Servicio Nacional de Geología y Minería (SERNAGEOMIN) en razón de su función de "velar porque se cumplan los reglamentos de policía y seguridad minera y aplicar las sanciones respectivas a sus infractores" (art. $2 \mathrm{~N}^{\circ} 8$ del D.L. 3.525). Al respecto, la Contraloría General de la República ha señalado que: "de la preceptiva reseñada es posible colegir que el Servicio Nacional de Geología y Minería constituye el organismo con competencia técnica en materia de fiscalización de la normativa sobre seguridad minera y está dotado de atribuciones vinculadas a la aprobación de proyectos de explotación, la inspección y fiscalización de estos, la imposición de medidas correctivas y la aplicación de sanciones" ${ }^{42}$. Con todo, de acuerdo a la jurisprudencia de la Corte Suprema, esta competencia "no se relaciona con la salud pública y las condiciones de salud en los lugares de trabajo" 43 , razón por la cual habría que interpretarla en términos estrictos de seguridad.

Específicamente, la aprobación del plan de mitigación de riesgos se concretaría a través de la emisión de un "Informe Técnico" conforme al

42 Contraloría General de la República (2013) Dictamen No 78.505. Disponible en www.contraloria.cl [fecha de visita 18 de abril de 2016].

43 Corte suprema. 29 de octubre de 2010. Rol No 3093 de 2010. Considerando 6․ Disponible en www.vlex.com [fecha de visita 6 de enero de 2017] 
Reglamento de Seguridad Minera (art. 13 letra c) ${ }^{44}$ y al Manual de Evaluación de Riesgos de Faenas Mineras Abandonadas o Paralizadas (FMA/P) ${ }^{45}$.

Así también, en materia marítima, dicha función correspondería a la Dirección General del Territorio Marítimo y de Marina Mercante (DIRECTEMAR) ${ }^{46}$.

\section{CONCLUSIONES}

De acuerdo a lo expuesto en este trabajo es posible destacar las siguientes conclusiones:

1. La suspensión de faenas ante accidentes fatales o graves prevista en el artículo 76 de la Ley 16.744 constituye una carga pública legal, ipso iure, conductual, suspensiva, y correctiva de un riesgo que goza de presunción simplemente legal. Ante su incumplimiento, este deber puede ser exigido a través de una orden directa o la imposición de una multa.

2. La expresión accidente "grave" ha sido objeto de múltiples interpretaciones por parte de la jurisprudencia administrativa y judicial. De ellas se desprende que el siniestro debe producir una incapacidad prolongada y severa en el trabajador. Por su parte, faena "afectada" es una actividad desarrollada en un lugar específico, que ha servido de ocasión para un accidente fatal o grave, causado presumiblemente y de modo directo por deficiencias o infracciones administrativas que afectan la salud o vida del trabajador.

3. El deber legal de suspensión se entendería incumplido en las siguientes tres hipótesis: a) no suspender inmediatamente o continuar desarrollando la actividad; b) suspender y reanudar la actividad sin autorización del fiscalizador; y c) realizar cualquier conducta inherente a dicha actividad, aunque no signifique reanudación, sin validación de la autoridad competente.

\footnotetext{
44 Presidente de la República. Ministerio de Minería (2002) Decreto Supremo No 132. "Fija texto refundido, sistematizado y coordinado del Decreto Supremo No 72, de 1985, del Ministerio de Minería, que establece el Reglamento de Seguridad Minera”. Santiago: Diario Oficial el 7 de febrero de 2004.

45 Servicio Nacional de Geología y Minería (2008) Manual de Evaluación de Riesgos de Faenas Mineras Abandonadas o Paralizadas. Disponible en www.sernageomin.cl [fecha de visita 18 de abril de 2016].

46 Presidente de la República. Ministerio de Marina (1953) Decreto con Fuerza de Ley $\mathrm{N}^{\circ}$ 2. "Ley Orgánica de la Dirección General del Territorio Marítimo y Marina Mercante". Santiago: Diario Oficial 5 de agosto de 1953. Art. 3.
} 
4. La realización de una actividad inherente a la faena suspendida no vulnera la suspensión en la medida que cumpla los siguientes requisitos: a) que sea necesaria para constatar o corregir deficiencias; b) que haya contado con un plan de prevención del riesgo prohibido que justificó la suspensión, revisado por autoridad competente; y c) que se haya cumplido dicho plan en la práctica.

\section{BIBLIOGRAFÍA}

\section{TEXTOS DOCTRINARIOS}

Alessandri R., Arturo; Somarriva U., Manuel; Vodanovic H., Antonio (2009) Tratado de Derecho Civil, Tomo Primero. Santiago: Editorial Jurídica de Chile, pp. 401.

Applebey, George (1979) "British Legislation on health and safety work: appraisal after five years". Les Cahiers de Droit, p. 708.

Domingo, Rafael y Rodríguez-Antolín, Beatriz (2000) Reglas jurídicas $y$ aforismos. Madrid: Editorial Aranzadi, p. 227.

HiLgerT, Jeffrey (2012-2013) "The future of workplace health and safety as a fundamental human right". Comparative Labor Law and Policy Journal, Vol. 34, pp. 715 a 736.

Hopkins, Andrew (2007) "Beyond compliance monitoring: new strategies for safety regulators", Law and Policy, $\mathrm{N}^{\circ} 29$, pp. 211-225.

Lagos Villareal, Osvaldo (2006) Las cargas del acreedor en el seguro de responsabilidad civil. Madrid: Fundación Mapfre. p. 502.

Leal VÁsquez, Brigitte (2015) La potestad de inspección de la Administración del Estado. Santiago: Cuadernos del Tribunal Constitucional. $\mathrm{N}^{\circ}$ 56. p. 289.

Mayer, Otto (1982) Derecho Administrativo Alemán. Tomo IV. Buenos Aires: Ediciones Depalma. pp. 374. pp. 107 y ss.

Real Academia Española (2001) Diccionario de la lengua española (22.a ed.). Consultado en http://www.rae.es/rae.html.

Tshoose, Clarence (2014) "Placing the Right to Occupational Health and Safety within a Human Rights Framework: Trendsand Challenges for South Africa", Comparative and International Law Journal of Southern Africa, Vol. 47, Issue 2, p. 276.

VAN Kerner, Esther (1997) "The right of an employee to stop work in dangerous circumstances at the workplace: an international perspective on south African law", Industrial Law Journal Juta, $\mathrm{N}^{\circ}$ 18, p. 1198. 


\section{ACTOS ESTATALES LEGISLATIVOS, ADMINISTRATIVOS Y JUDICIALES}

Congreso Nacional (1968) Ley No 16.744. "Establece normas sobre accidentes del trabajo y enfermedades profesionales". Santiago: Diario Oficial 1 de enero de 1968.

Congreso Nacional. Ministerio de Salud Pública (1968) D.F.L. N ${ }^{\circ}$ 725. "Código Sanitario". Santiago: Diario Oficial, 31 de enero de 1968.

Contraloría General de la República (2013) Dictamen No 78.505. Disponible en www.contraloria.cl [fecha de visita 18 de abril de 2016].

Corte de Apelaciones de Iquique. 3 de julio de 2015. Rol No 32. Resolución $\mathrm{N}^{\circ}$ 9.404. Disponible en www.vlex.com [fecha de visita 18 de abril de 2016].

Corte de Apelaciones de Temuco. 22 de marzo de 2011. Rol No 1127-2010. Disponible en www.vlex.com [fecha de visita 18 de abril de 2016].

Dirección del Trabajo (2007) Orden de servicio $\mathrm{N}^{\circ}$ 7. "Imparte criterios de actuación e instrucciones para la aplicación de las normas referidas a la obligación de notificación de accidentes del trabajo fatales y graves y la obligación de autosuspensión de la obra o faena”. Disponible en www.dt.gob.cl [fecha de visita 18 de abril de 2016].

Dirección General de Obras Públicas (2009) Resolución Nº 258 "Modifica y fija el texto refundido de la Resolución No 48 de 2009 sobre Bases Administrativas para Contratos de Obras Públicas, Construcción y Conservación y fija texto refundido de la citada Resolución DGOP No 48, y sus modificaciones". Disponible en http://fiscalia.mop.cl [fecha de visita 18 de abril de 2016].

Juzgado de Letras del Trabajo de Concepción. 23 de noviembre de 2010. Rol No I-13-2010. Disponible en www.vlex.cl [fecha de visita 18 de abril de 2016].

Juzgado de Letras del Trabajo de Curicó. 14 de octubre de 2009. Rol No I-8-2009. Disponible en www.vlex.com [fecha de visita 18 de abril de 2016].

Juzgado de Letras del Trabajo de Temuco. 8 de febrero de 2013. Rol $\mathrm{N}^{\circ}$ I-105-2012. Disponible en www.vlex.com [fecha de visita 18 de abril de 2016].

Juzgado de Letras del Trabajo de Temuco. 21 de diciembre de 2012. Rol No I-83-2012. Disponible en www.vlex.com [fecha de visita 18 de abril de 2016].

Juzgado de Letras y Garantía de Quintero. 22 de marzo de 2013. Rol N I-2-2012. Disponible en www.vlex.com [fecha de visita 18 de abril de 2016]. 
Juzgado de Letras del Trabajo de Iquique. 25 de julio de 2011. Rol No I-4-2011. Disponible en www.vlex.com [fecha de visita 18 de abril de 2016].

Juzgado de Letras del Trabajo de Calama. 20 de marzo de 2014. Rol No I-22-2013. Disponible en www.vlex.com [fecha de visita 18 de abril de 2016].

Juzgado de Letras del Trabajo de Calama. 20 de marzo de 2014. Rol $\mathrm{N}^{\circ}$ I-22-2013. Disponible en www.vlex.com [fecha de visita 18 de abril de 2016].

Juzgado de Letras del Trabajo de Talca. 19 de octubre de 2009. Rol $\mathrm{N}^{\circ}$ I-6-2009. Disponible en www.vlex.com [fecha de visita 18 de abril de 2016].

Presidente de la República. Ministerio de Marina (1953) Decreto con Fuerza de Ley $\mathrm{N}^{\circ}$ 2. "Ley Orgánica de la Dirección General del Territorio Marítimo y Marina Mercante". Santiago: Diario Oficial 5 de agosto de 1953.

Presidente de la República. Ministerio de Minería (2002) Decreto Supremo No 132. "Fija texto refundido, sistematizado y coordinado del Decreto Supremo No 72, de 1985, del Ministerio de Minería, que establece el Reglamento de Seguridad Minera”. Santiago: Diario Oficial el 7 de febrero de 2004.

Presidente de la República. Ministerio del Trabajo y Previsión Social (1967) Decreto con Fuerza de Ley No 2. "Dispone la reestructuración y fija las funciones de la Dirección del Trabajo". Santiago: Diario Oficial 29 de septiembre de 1967.

Primer Juzgado de Letras de Coronel. 21 de octubre de 2014. Rol $\mathrm{N}^{\circ}$ I-11-2014. Disponible en www.vlex.com [fecha de visita 18 de abril de 2016].

Primer Juzgado de Letras de Santa Cruz. 29 de enero de 2015. Rol $\mathrm{N}^{\circ}$ I-25-2014. Disponible en www.vlex.com [fecha de visita 18 de abril de 2016].

Primer Juzgado de Letras del Trabajo de Santiago. 5 de mayo de 2015. Rol No I- 29-2015. Disponible en www.vlex.com [fecha de visita 18 de abril de 2016].

Segundo Juzgado de Letras del Trabajo de Santiago. 18 de julio de 2014. Rol No I-184-2014. Disponible en www.vlex.com [fecha de visita 18 de abril de 2016].

Servicio Nacional de Geología y Minería (2008) Manual de Evaluación de Riesgos de Faenas Mineras Abandonadas o Paralizadas. Disponible en www.sernageomin.cl [fecha de visita 18 de abril de 2016].

Superintendencia de Seguridad Social (2007) Circular No 2.345. "Imparte instrucciones respecto de las obligaciones impuestas a las empresas por los incisos cuarto y quinto del artículo 76 de la ley $\mathrm{N}^{\circ}$ 
16.744, en virtud de lo establecido en la ley $\mathrm{N}^{\circ} 20.123$ ”. Disponible en www.suseso.cl [fecha de visita 18 de abril de 2016].

Superintendencia de Seguridad Social (2007) Circular $N^{\circ} 2.378$. "Complementa instrucciones impartidas mediante circular $\mathrm{N}^{\circ} 2.345$, de 10 de enero de 2007, respecto de las obligaciones impuestas a las empresas por los incisos cuarto y quinto del artículo 76 de la ley $\mathrm{N}^{\circ}$ 16.744, en virtud de lo establecido en la ley $N^{\circ} 20.123$ ”. Disponible en www.suseso.cl [fecha de visita 18 de abril de 2016].

Superintendencia de Seguridad Social (2010) Ordinario No 52.849. Disponible en www.suseso.cl [fecha de visita 18 de abril de 2016].

Tribunal Constitucional. 10 de noviembre de 2013. Rol No 2.264.

"Requerimiento de inaplicabilidad por inconstitucionalidad presentado por CGE Distribución S.A. respecto del artículo 15, inciso primero, de la Ley No 18.410, que crea la Superintendencia de Electricidad y Combustibles". Disponible en www.tribunalconstitucional.cl [fecha de visita 18 de abril de 2016]. 